\title{
Hazardous Waste Vitrification by Plasma Gasification Process
}

\author{
Anyaegbunam F. N. C. (Ph.D.) \\ Department of Physics/Geology/Geophysics, Federal University Ndufu-Alike Ikwo (FUNAI), Abakaliki, Ebonyi \\ State, Nigeria.
}

\begin{abstract}
Hazardous Wastes Control is one of the major problems of waste management companies and governmentand environment and disposal of such hazardous wastes is critical and problematic. Current method of hazardous waste disposal, which include mass burn or incineration, and landfilling create new problems to the environment. Vitrification of such wastes by thermal plasma gasification process appears to be a solution to hazardous waste disposal that does not create further problems to the environment. The energy generated by plasma arcs has been recently applied to hazardous waste vitrification. The technology involves subjecting waste material to high temperatures with the purpose of immobilizing nonvolatile chemical species into a nonleachable matrix. Plasma arc gasification and vitrification processes are well known for special waste disposal requirements. This paper presents the high tech plasma gasification processas an efficient technological tool for hazardous waste destruction, such as hospital wastes, nuclear wastes, pyrotechnic smoke assemblies, thermal batteries, and other military wastes. Results show that thermal plasma gasification process is effective in hazardous waste vitrification.
\end{abstract}

Key Words: plasma gasification, plasma torch, hazardous waste, vitrification, slag.

\section{Introduction}

Some of the illustrative examples defining the magnitude of the hazardous waste disposal issue facing both governmental and private organizations are seen from accumulating stockpiles, high storage costs, and the potential for long-term liability. Hazardous materials such as found in hospital wastes, military wastes, nuclear wastes and asbestos from demolished buildings have always posed a great danger to health and environment. The U.S. Environmental Protection Agency (EPA) has identified eight Toxicity Characteristic Leaching Procedure (TCLP) metals which represent environmental hazards and whose disposal are strictly regulated, [1], [2],[3]. Summary ofprevalence of these metals in various military and hospital applications and their permissible concentrations according to EPA regulations are shown in Table 1.

Table 1: Tclp Standards (Us.Epa)

\begin{tabular}{|c|c|}
\hline Heavy Metal & Permissible Concentration (mg/l) \\
\hline Arsenic & 5.0 \\
\hline Barium & 100.0 \\
\hline Cadmium & 1.0 \\
\hline Chromium & 5.0 \\
\hline Lead & 5.0 \\
\hline Mercury & 0.2 \\
\hline Selenium & 1.0 \\
\hline Silver & 5.0 \\
\hline
\end{tabular}

One of the technical challenges in disposing of hazardous wastes is the wide variability in waste media. Hazardous waste may either be solid or liquid waste streams or may contain such environmental hazards as asbestos, heavy metals, or organics or any combination of the mentioned waste components. In 1994, for example, the U.S. Army generated 640 tons of multi-phase toxic containerized liquids, 523 tons of bulk toxic pumpable liquids, 530 tons of multi-phase containerized solvents, and 128 tons of pumpable solvents. Current treatment of these liquid containing waste streams cost approximately $\$ 1250$ to $\$ 2700$ per ton [1],[2],[3],[4]. Various waste treatment/disposal methodologies have and continue to be evaluated for the environmental remediation of hazardous contaminated materials. Plasma arc technology has been identified as one safe and effective tool for the conversion of contaminated media into chemically inert solids no longer requiring disposal in EPA hazardous waste approved landfills. The technology involves vitrification of hazardous wastes by plasma gasification process.

This paper posits that high tech plasma gasification process is an efficient technological tool for hazardous waste destruction via vitrification. 


\section{Thermal Plasma Gasification Process}

Thermal Plasma gasification process is an efficient and environmentally responsible form of thermal treatment [2] of wastes which occurs in oxygen starved environment so that waste is gasified, not incinerated.A plasma is an electrically conductive gas in which an important fraction is ionized. Plasmas are generated when an electromagnetic force causes electrons to be pulled apart from atomic nuclei resulting in an ionized gas. In plasma arc technology, a torch is used to generate controllable plasma temperatures in the range from $1500^{\circ} \mathrm{C}$ to $10,000^{\prime}$ C. Several processing benefits associated with plasma technology include high thermal efficiency (resulting in fast reaction kinetics); flexibility in choice of process gas environment; substantial waste volume reduction; high energy density, thus adequacy in utilizing smaller processing reactors; no material pretreatment is required; and the need for less pollution abatement equipment due to the lower demand for air and absence of fossil fuels. In plasma gasification process, the contaminated waste material is subjected to the high temperatures of the plasma from plasma torch and chemically combining the non-volatile components into a matrix material, such as soil, so that the processed material, upon solidification, represents an inert, chemically stable material. The resulting matrices will immobilize the hazardous components and prevent them from further contamination of the environment. The resulting vitrified residue is called the slag which is environmentally benign. Thus, the original hazardous waste is then destroyed via vitrification.

Plasma gasification represents a clean and efficient option to manage waste in an environmentally responsible manner. The plasma gasification technology is ideally suited to process waste such as Municipal Solid Waste ("MSW"), common hazardous waste found in hospitals and military establishments, industrial waste, chemical waste, some nuclear wastes, sediment sludge and biomass. It can also vitrify fly ash from incinerators and any other types of ash [3]. During the actual processing of the hazardous waste, a plasma torch is used to generate the high temperatures (typically several thousand degrees Centigrade) necessary to break the chemical bonds present in the waste material, [2],[5]. The extremely intense energy produced by the torch is powerful enough to disintegrate the hazardous waste into its component elements. The subsequent reaction in the presence of controlled amount of oxygen produces syngas which leaves the furnace at the top for further treatment, and the byproducts consisting of a vitrified glass-like substance called the slag, which is collected at the bottom of the furnace and used as raw materials for construction. The plasma treated melt is tapped out of the processing chamber or furnace bottom. Once cooled, the solidified mass, referred to as the slag, can be characterized as a vitrified, or glass-like rock. More importantly, however, once thermal plasma processed, the original hazardous waste now exists as a non-hazardous, benign residue. Various feasibility studies $[6],[7],[8],[9],[10]$ have indicated the consistency of slag products to pass toxicity characteristic leaching procedure (TCLP) and durability testing.

\section{Materials And Methods}

Plasma gasification process is an efficient and environmentally responsible form of thermal treatment [3],[9] of hazardous wastes which occurs in oxygen starved environment so that the waste is destroyed by the intense heat from plasma torch. The heart of the plasma process is the "Plasma Furnace", Fig.1; a vertical refractory lined vessel into which the contaminated waste material is introduced near the top along with metallurgical coke and limestone. Plasma torches are located near the bottom of the furnace and direct the high temperature process gas into a bed of coke at the bottom of the vessel. Air or oxygen is introduced through tuyres located above the torches. The high temperature process gas introduced through the torch raises the temperature of the coke bed to a very high level to provide a heat reservoir, and the process gas moves upward through the furnace vessel to vitrify the waste. The power of thermal plasma process makes it environmentally clean technique. Plasma Gasification Processes (PGP)are being developed by many gas plasma technology companies for Waste destruction, [12]. 


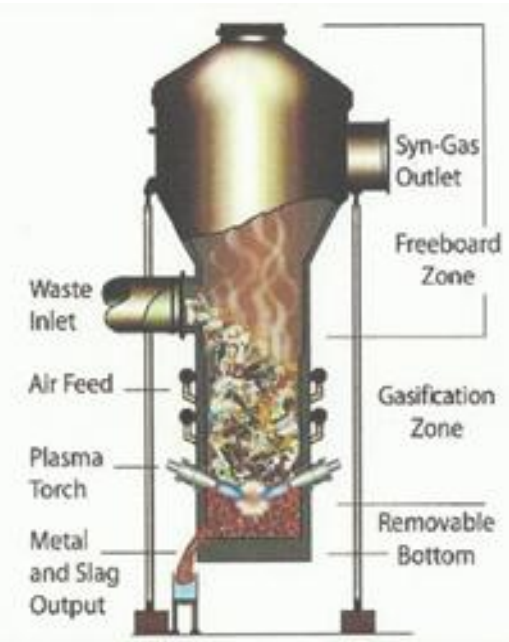

Fig. 1: The Plasma Furnace

The plasma treated melt is tapped out of the processing chamber or furnace bottom. Once cooled, the solidified mass, referred to as the slag, can be characterized as a vitrified, or glass-like rock. That is the inorganic materials such as metal, glass and soil that could not gasify are melted and produce a two phase liquid stream consisting of recyclable metals and a vitrified glass-like residue that flows to the bottom of the vessel [4]. Discharge of the molten material into water results in the formation of metal nodules and a coarse rock-like substance which is environmentally benign. More importantly, however, once thermal plasma processed, the original hazardous waste now exists as a non-hazardous, benign residue. Various feasibility studies $[6],[7],[8],[9],[10]$ have indicated the consistency of slag products to pass toxicity characteristic leaching procedure (TCLP) and durability testing. Highly volatile chemical species can escape out of the main reaction chamber before they are combined into the melt. Consequently, output-gas treatment systems are used to trap particulate and destroy any residual organics before they are released into the atmosphere. Plasma system design engineers have developed output-gas treatment units which can meet the emissions controls requirements of plasma gasification processing yet keep the costs reasonable so that the vitrification process remains an economic feasibility. An overview of some gaseous monitoring and emissions control methodologies used in plasma systems are reported in [9].

The hot output syngas leaving at the top of the furnace is cooled and pass through cleaning and emission control processes to remove particulate matter and other toxic substances before passing to other desired conversion subsystems. Thus emissions to the environment are greatly reduced and kept under acceptable levels.

Thermal Plasma process emission products measured included particulate matter, NOx, SOx, hydrochloric acid, and trace amounts of mercury and dioxins/furans; in all cases emissions were well below applicable standards (Tables 2-4).

Table 2:Epa Verification Testing Of Thermal Plasma Process For 10 Tpd Of Circuit Boards.

\begin{tabular}{|c|c|c|}
\hline Emissions (mg/N-M3@7\% O2) & Measured & USEPA Standard \\
\hline PM & 3.3 & 40.6 \\
\hline HCL & 6.6 & 308 \\
\hline NOx & 74 & 85.7 \\
\hline Sox & - & 50 \\
\hline Hg & 0.0002 & 13 \\
\hline
\end{tabular}

Table 3: Epa Verification Testing Of Thermal Plasma Process For 10 Tpd Of Medical Waste,

\begin{tabular}{|c|c|c|}
\hline Emissions (mg/N-M3@7\%O2) & Measured & USEPA Standard \\
\hline PM & $<3.3$ & 40.6 \\
\hline HCL & 2.7 & 308 \\
\hline NOx & 162 & 85.7 \\
\hline Sox & - & 50 \\
\hline Hg & 0.00067 & 13 \\
\hline
\end{tabular}


Table 4: Results Of Third-Party Demonstration Of Plasco Energy Thermal Plasma Process Gasification

Of 110 Tpd Of Msw, Ottawa, Canada

\begin{tabular}{|c|c|c|}
\hline Emissions (mg/N-M3@7\%O2) & Measured & EC 2000/76 Standard \\
\hline PM & 12.8 & 14 \\
\hline HCL & 3.1 & 14 \\
\hline NOx & 150 & 281 \\
\hline Sox & 26 & 70 \\
\hline Hg & 0.0002 & 14 \\
\hline Dioxins/furans (ng/N-m3) & 0.009245 & 0.14 \\
\hline
\end{tabular}

Again, ToxicityCharacteristics Leaching Procedure (TCLP) text results for heavy metals (Arsenic, Barium, Cadmium, Chromium, Lead, Mercury, Selenium and Silver) present after plasma gasification process in experiments with soil and without soil are below detectable levels (BDL) in both experiments, and also far below the permissible standards established by the US EPA, see Tables 5 and 6.

Table 5: Tclp Results For Experiment (Without Soil)

\begin{tabular}{|c|c|c|}
\hline Heavy Metal & Permissible Concentration (mg/l) & Measwured Concentration (mg/l) \\
\hline Arsenic & 5.0 & BDL (0.1) \\
\hline Barium & 100.0 & 0.47 \\
\hline Cadmium & 1.0 & BDL (0.1) \\
\hline Chromium & 5.0 & BDL (0.1) \\
\hline Lead & 5.0 & BDL (0.1) \\
\hline Mercury & 0.2 & BDL (0.01) \\
\hline Selenium & 1.0 & BDL (0.2) \\
\hline Silver & 5.0 & BDL (0.1) \\
\hline
\end{tabular}

BDL = Below Detectable Level

Table 6: Tclp Results For (With Soil)

\begin{tabular}{|c|c|c|}
\hline Heavy Metal & Permissible Concentration (mg/l) & Measured Concentration (mg/l) \\
\hline Arsenic & 5.0 & BDL (0.1) \\
\hline Barium & 100.0 & BDL $(0.1)$ \\
\hline Cadmium & 1.0 & BDL (0.1) \\
\hline Chromium & 5.0 & BDL $(0.1)$ \\
\hline Lead & 5.0 & BDL $(0.1)$ \\
\hline Mercury & 0.2 & BDL (0.01) \\
\hline Selenium & 1.0 & BDL (0.2) \\
\hline Silver & 5.0 & BDL (0.1) \\
\hline
\end{tabular}

BDL = Below Detectable Level

\subsection{Plasma Vitrification of Asbestos}

Asbestos fibers and asbestos contaminated materials are tightly regulated as they are carcinogenic. Currently,asbestos removed from both public and private buildings must be deposited in Class I EPA regulated landfills.As landfill charges are volumetrically based, disposal of asbestos can be costly. With the possibility of reducedor prohibited use of Class I landfills, alternative means of dealing with asbestos contaminated materials areurgently needed.

Since 1989, the U.S. Army Corps of Engineers have supported a Construction Productivity AdvancementResearch Project (CPAR) utilizing plasma arc technology for the conversion of asbestos into harmless rock-likeproducts. The CPAR project was conducted under the coordination of USACERL and the Georgia Institute ofTechnology using one of Plasma Energy Corporation's torch systems [10],[11]. The experimental results of the firststage of this two-phase program indicated that plasma arc technology provided successful immobilization of chrysotile asbestos while meeting the standards for asbestos exposure. An economic analysis of the plasmaprocessing of asbestos yielded positive indications for the success of a mobile plasma asbestos pyrolysis system

(PAPS). It was concluded that a PAPS would be an economically competitive alternative to landfllling asbestoscontaminated material. The attractiveness of the technology is apparent when the ever increasing costs forhazardous waste liability and transportation to appropriate landfill sites are considered. Plasma vitrification of asbestos thus proves to be an environmentally responsible method of destroying such hazardous waste. 


\section{Conclusion}

Method of vitrification of hazardous waste materials by plasma gasification process has been presented. It is found that the final vitrified rock-like product is environmentally benign. Various experiments conducted on the vitrified residue show that high tech plasma gasification process is an efficient technological tool for hazardous waste destruction via vitrification. Environmental hazards of hospital wastes, asbestos from demolished buildings, and hazardous wastes from military establishments could not be mitigated by landfilling alone. It is found that thermal plasma gasification process is an effective tool for the treatment of all types of wastes including carcinogenic types such as asbestos. Plasma arc technology is a thermal treatment tool capable of safely and efficiently processing materials containing a large variety of environmental hazards such as heavy metals and asbestos. It is observed that Toxicity Characteristics Leaching Procedure (TCLP) text results for heavy metals (Arsenic, Barium, Cadmium, Chromium, Lead, Mercury, Selenium and Silver) present after plasma gasification process in experiments with soil and without soil are below detectable levels (BDL) in both experiments, and also far below the permissible standards established by the US EPA. The experiment with soil was tosimulate the real situation.Utilization of gasification technology allows hazardous waste materials to be safely transformed into non-hazardous, vitrified glass-like rock which is suitable and environmentally benign. The extensive use of plasma gasification technology by gas-plasma organizations for the destruction of hazardous waste, illustrate the potential and feasibility of the technology to meet the ever growing waste disposal needs of an environmentally conscious world community.

Having passed the environmental profile tests, thermal plasma gasification process may in the near future prove to be a unique environmentally safe and economically viable tool for handling all types of waste media. Like any new technology, adoption and wider use of this technology shall lead to mass production and significant cost reduction.

\section{References}

[1]. Anyaegbunam F.N.C., (2013), Environmentally Friendly and Sustainable Municipal Solid Waste Management in Abuja. International Journal of Engineering and Science Invention (IJESI), Volume 2 July 2013, $\mathrm{PP}_{42-50}$.

[2]. Anyaegbunam Felix N.C. (2013), Plasma Gasification for waste management and sustainable renewable clean energy generation. In Proceedings of Nigerian Academy of Science, Vol.6, Issue 1, 2013, $\mathrm{PP}_{33-50}$.

[3]. Anyaegbunam F.N.C., (2013), Plasma Gasification for Waste Destruction and Power Generation in Nigeria. International Journal of Engineering Research \& Technology, Vol.2 issue 7 July 2013, pp $_{1067-1079 .}$

[4]. Anyaegbunam F.N.C., (2014), Thermal Plasma Process for Hazardous Waste Treatment. International Journal of Engineering Research \& Technology, Vol.3 issue 3 March 2014, pp

[5]. Camacho, S.L. (1995), "The Plasma Arc Torch, Its Electrical and Thermal Characteristics," in Proceedings of the International Symposium on Environmental Technologies: Plasma Systems and Applications, Georgia Institute of Technology Research Corporation, Atlanta, GA, Oct. 1995, pp. 45-66.

[6]. Environmental Protection Agency (US), 'Superfbnd Innovative Technology Evaluation Program.

[7]. Technology Profiles, Seventh Edition," Office of Research and Development, Washington, DC, Nov. 1994 (EPA/540/R-94/526).

[8]. Freeman, D.J. and Zaghloul, H.H., 'Evaluation of Plasma Arc Pyrolysis for the Destruction of Hazardous Military Wastes,"in Proceedings of the 86th Annual Meeting of the Air \& Waste Management Association,

[9]. Denver, CO, 1993.

[10]. Zaghloul, H.H. and Circeo, L.J. (1993), 'Destruction and Vitrification of Asbestos Using Plasma Arc Technology," U.S. Army Construction Engineering Research Laboratories, Champaign, IL (USACERL Technical Report CPAR-TR-EP-93/01), 1993.

[11]. Proceedings of the International Symposium on Environmental Technologies: Plasma Systems and Applications, published by the Georgia Institute of Technology Research Corporation, Atlanta, GA, Oct. 1995.

[12]. Smith, E.D. and Zaghloul, H.H. (1994)-, 'Applying Plasma Arc Technology to Asbestos Cleanup," Federal Facilities Environmental Journal, Spring 1994, pp. 43-52.

[13]. Circeo, L.J. and Newsom, R1A., 'Destruction of Asbestos-Containing Materials Using Plasma Arc

[14]. Technology," Final Report, USACERL CPAR Program Report No. CPAR-D48-AO8, Champaign, IL,

[15]. 1996.

[16]. Dighe, Shyam V. (2008), Westinghouse Plasma Corporation, Madison, Pennsylvania, USA, Plasma Gassification : a proven technology, Proceedings of NAWTEC16, 16th Annual North American Waste-to-Energy Conference, May 19-21, 2008, Philadelphia, Pennsylvania, USA. 